\title{
An Improvement on Route Recovery by Using Triangular Fuzzy Numbers on Route Errors in MANET
}

\author{
Sara Aliabadi ${ }^{1}$, Mehdi Agha Sarram ${ }^{1}$ \\ ${ }^{1}$ Department of Computer Science, Islamic Azad University Science and Research Branch Yazd, Yazd, Iran
}

\begin{abstract}
Based on mobile nature in MANET, there is no doubt that all routing protocols have some route errors. Usually, routing protocols try to recover a route after a route error has been happened on an exact route to destination. This kind of route recovery could make more packet loss and also more time waste. This project adds Triangular Fuzzy Numbers to prediction of route errors and make route recovery as parallel of packet sending. Indeed, any node in this project uses a route error counter and an error prediction based on Fuzzy algorithm to recover its routes before an exact route error on its route discovery has been happened. There is no doubt that using suggested prediction cannot solve all route errors; but it could help routing protocols to improve their route recovery algorithm. This project uses DSR as one of the standard MANET routing protocols to simulate the results.
\end{abstract}

Keywords: MANET, Fuzzy, Triangular Numbers, DSR, Routing

\section{Introduction}

A wireless mobile ad hoc network (MANET) is a particular type of wireless network in which an association of mobile nodes forms a multi-hop radio temporary network in a decentralize manner without any support of a fixed infrastructure. Each mobile node acts as both a terminal and a router, and the control of the network activity is distributed to these nodes. Mobile nodes communicate over wireless links which typically have less bandwidth than wired networks. In addition, mobile nodes have lower battery power and lower computation ability. The network topology is generally dynamic because the connectivity among the nodes may change with time due to nodal mobility, the effect ofradio communication, and power limitations. Thesefeatures of MANET have posed a lot of challenges indesigning an effective, reliable and scalable routingprotocol.

Lost routes recovery is one of the major challenges in MANET routing protocols which could make a route more or less effective on packet loss during packet sending. Usually, routing protocols in MANET provide route error to inform other nodes that a node is gone and route through that node are not usable any more. In this case, node will recover their routes after a route error has been happened. Thus, packets which are sent during route recovery will lose.

A fuzzy number is a quantity whose value is imprecise, rather than exact as is the case with "ordinary" (single-valued) numbers. Any fuzzy number can be thought of as a function whose domain is a specified set (usually the set of real numbers, and whose range is the span of non-negative real numbers. Triangular Fuzzy Numbers use three sets of value to estimate the average situation of any system.

First part of this article is to explain DSR and how it works. Then, the second part is going to determine Fuzzy Triangular Numbers and project suggestion to predict route error. Finally, we simulate our findings by NS2 to prove our recovery improvement on MANET routing.

\section{DSR}

A Mobile Ad Hoc Network, also called a MANET, is an autonomous collection of mobile nodes forming a dynamic wireless network. The administration of such a network is decentralized. In this kind of network each node acts both as host and router and forwards packets for nodes that are not within transmission range of each other. A MANET provides a practical way to rapidly build a decentralized communication network in areas where there is no existing infrastructure or where temporary connectivity is needed.

The changing topology of MANETs and use of the wireless medium justify the need fordifferent routing protocols than those developed for wired networks or multi-cell environments.Various routing protocols have been proposed in the IETF MANET working group to addressthe problem of decentralized routing.

The Dynamic Source Routing (DSR) protocol was designed especially for MANET applications. Its main feature is that every data packet follows the source route stored in its header. This route gives the address of each node through which the packet should be forwarded in order to reach its final destination. Each node on the path has a routing role and must transmit the packet to the next hop identified in the source route. 
Each node maintains a Route Cache in which it stores every source route it has learned. When a node needs to send a data packet, it checks first its route cache for a source route to the destination. If no route is found, it attempts to find one using the route discovery mechanism.

A monitoring mechanism, called route maintenance, is used in each operation along a route. This mechanism checks the validity of each route used.

The route maintenance mechanism ensures that the paths stored in the route cache are valid. If the data link layer of a node detects a transmission error, the node creates a Route Error packet and transmits it to the original sender of the data packet. This Route Error packet indicates which link is "broken". When a node receives a Route Error packet, it removes the link in error from its route cache and for each route containing this link, truncates the route from the hop before the broken link.

\section{Fuzzy Triangular Numbers and Recovery Algorithm}

Route updating can help routing protocols to reduce packet loss and improve QoS. Indeed, MANETs have a mobile nature; so topology changes in them frequently. This mobile nature effects on the routes and make them unusable after a while. So, all MANET routing protocols need a route updating algorithm.

In this project, we use Triangular Fuzzy Numbers to make the route updating time dependent. In this case, we forecast a time for route updating and make this time error dependent based on Triangular Numbers. If the route error came from a direct node in a route, other nodes will update that route immediately. Otherwise, nodes which received route error will increase their route error counter and operate triangular equation. The result of Triangular equation should multiply to forecast time and subtract from it.

In order to consider the fuzzy route recovery using the triangular fuzzy numbers which were based on statistical data, we need the following definitions.

Definition 1: A fuzzy set is called a level $\alpha$ fuzzy interval, where $0 \leq \alpha \leq 1$ and we denote it by [p,q; $\alpha$ ], if its membership function is:

$\mu_{[p, q ; \alpha]}(x)=\left\{\begin{array}{lr}\alpha & \text { IF } p \leq x \leq q \\ 0 & \text { Otherwise }\end{array}\right.$

Definition 2: ã is called a fuzzy point, if its membership function on $\mathrm{R}=(-\infty, \infty)$ is

$\mu_{\tilde{\mathrm{a}}}(x)= \begin{cases}1 & \text { If } x=a \\ 0 & \text { if } x \neq a\end{cases}$

The family of all fuzzy sets on $\mathrm{R}$ which we denote as $F_{S}$ satisfies the following two conditions. Let DEFs. ThenDsatisfies $\left(1^{0}\right)$ and $\left(2^{0}\right)$ below.

$\left(1^{0}\right)$ The left and right hand side of the $\alpha$-level set of $\mathrm{D}, D_{l}(\alpha)$ and $D_{r}(\alpha)$ exist. We denoteit as $\mathrm{D}(\alpha)=$ $\left[D_{l}(\alpha), D_{r}(\alpha)\right]$.

$\left(2^{0}\right) D_{l}(\alpha)$ and $D_{r}(\alpha)$ are integrable for $\alpha \in[0,1]$.

By using Triangular definition, we can reach the following equation to guess when a route protocol should update or recover its route table.

$\operatorname{tri}_{(x ; m, a, b)}=\left\{\begin{array}{cc}x \leq a \\ \frac{x-a}{m-a} & x \in(a, m], a \neq m \\ \frac{b-x}{b-m} & x \in(m, b], m \neq b \\ 1 & x \geq b\end{array}\right.$

By using equation 3, we can divide mobile network errors to five parts. First, if the error comes from exact node on the route, other nodes will recover their routes immediately. Otherwise, they count the route errors and put the counter in equation 3. In this case, if the route errors were less than a, the network is safe and they do recovery as usual. While, if the route errors go over than a and less than $\mathrm{m}$, they will multiply the result of equation 3 to their usual recovery time and subtract the result from left recovery time. It will be same for route errors which are more than $\mathrm{m}$ and less than $\mathrm{b}$. For route errors which are more or equal by $\mathrm{b}$, the network is not safe and nodes will recover their route immediately. Note that, in this case, the route error counter will be change to zero after any route recovery.

\section{Simulation Results}

We addour findings on DSR and simulated it by NS2 for 5, 10, 15, 20, 25, 30, 35, and 40 nodes. Whereas every simulation results may have some exceptions, we simulated the F-DSR in some times and made our decision based on their average.

\subsection{End to End Delay}

End to End Delay is the most important result to prove the success of each routing protocol. The results of simulation show that the F-DSR works more proper than standard DSR. We can see that the End to End Delay in F-DSR is less than Standard DSR. Also, F-DSR has more success during node population increment. 


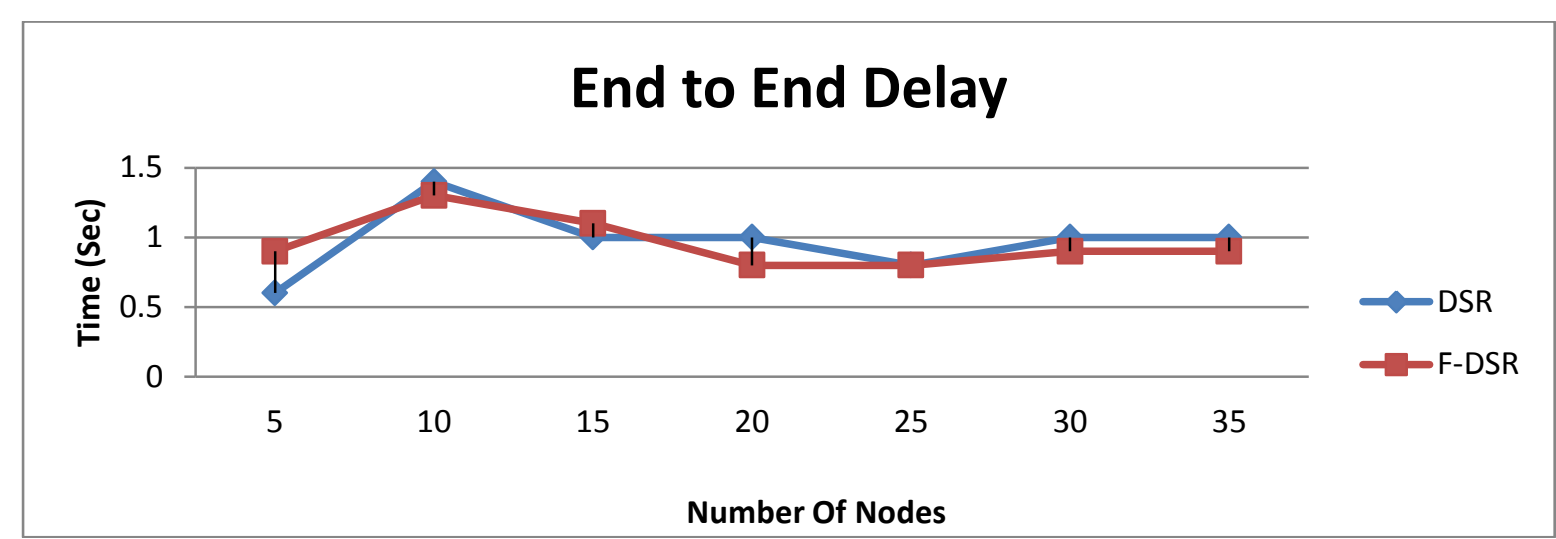

\subsection{Packet Delivery Rate}

Packet Delivery Rate is our final comparison between F-DSR and Standard DSR. There is no doubt that the results of simulation show that the packet delivery rate increased in F-DSR compare on Standard ones.

\section{Packet Delivery Rate (\% Successed Packets / Number of Nodes)}

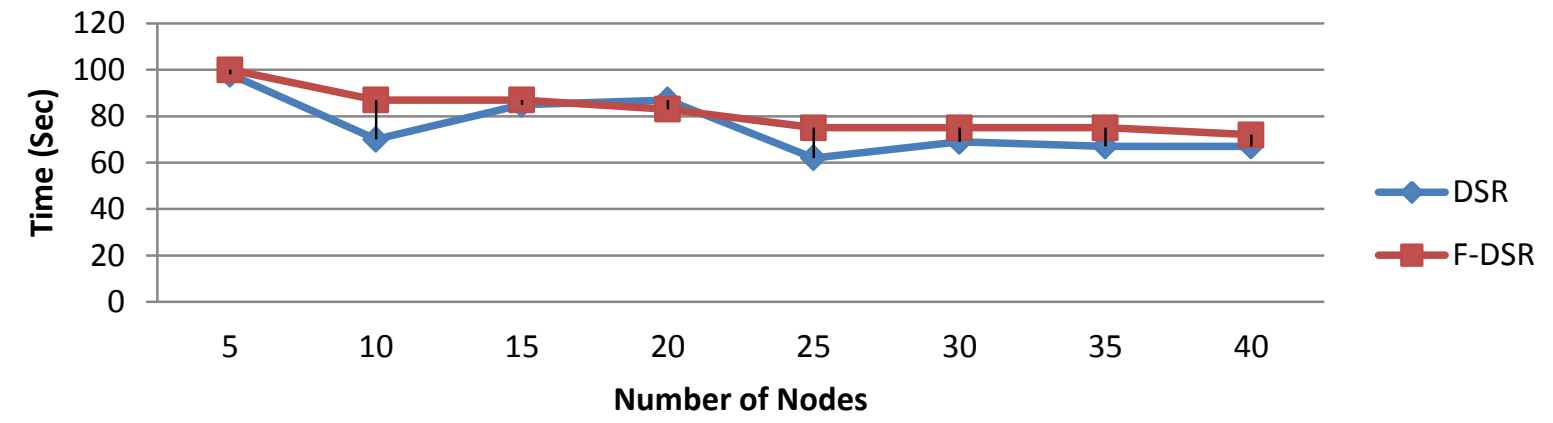

V.

Conclusion

Based on MANET mobility nature, there is always some route errors during packet sending. Usually, MANET routing protocols recover their routes after a route error has been happened. This kind of route recovery may cause to increase packet loss during packet sending. In this project we added Fuzzy Triangular Numbers into routing protocols in MANET to predict route errors and do route update in parallel of packet sending. For simulating our findings, we added our error prediction in DSR and simulated it by NS2. The results show that our route recovery algorithm can help DSR to reduce packet loss percentage and end to end delay by parallel route recovery.

\section{Reference}

[1] Abdullah, J., (2010), Multiobjectives GA-Based QOS Routing Protocol for Mobile Ad Hoc Network, International Journal of Grid and Distributed Computing, 3(4), 57-68.

[2] Aghdasi, H. S., Torabi, N., Rahmanzadeh, A., Aminiazar, M., and Abbaspour, M., (2012), Usefulness of multicast routing protocols for vehicular Ad-hoc networks, Sixth International Symposium Telecommunications (IST), 459-463.

[3] Ahn, Ch. W., and Ramakrishna, R. S., (2002), A Genetic Algorithm for Shortest Path Routing Problem and the Sizing of Populations, IEEE TRANSACTIONS ON EVOLUTIONARY COMPUTATION, 6(6), 132-138.

[4] Ahn, Ch., W., and Ramakrishna, R., S., (2002), A Genetic Algorithm for Shortest Path Routing Problem and the Sizing of Populations, IEEE TRANSACTIONS ON EVOLUTIONARY COMPUTATION, 6(6), 566-579.

[5] Al-Ghazal, M., El-Sayed, A., and Kelash, H., (2007), Routing Optimlzation using Genetic Algorlthm in Ad Hoc Networks, IEEE International Symposium on Signal Processing and Information Technology, 497-503.

[6] Alzate, M., A., Salamanca, M., P., Pena, N., M., and Labrador, M., A., (2007), End-to-End Mean Bandwidth Estimation as a Function of Packet Length in Mobile Ad Hoc Networks, IEEE, 415-420.

[7] Anand, V., Sairam, N., and Thiagajan, M., (2012), A Review of Routing in Ad Hoc Networks, Research Journal of Applied Sciences, Engineering and Technology, 4(8), 981-986.

[8] Artimy, M., M., Robertson, W., and Philips, W., j., (2006), Assignment of Dynamic Transmission Range Based on Estimation of Vehicle Density, Engineering Mathematics and Internetworking, 40-48.

[9] Barati, J., (2011), Evaluation of intelligent algorithms in Routing Mobile Ad hoc Networks, Mashhad PayamNour University.

[10] Barolli, A., Takizawa, M., Xhafa, F., and Barolli, L., (2010), Application of Genetic Algorithms for QoS Routing in Mobile Ad-Hoc Networks: A Survey, International Conference on Broadband, Wireless Computing, Communication and Applications, 250-259. 
[11] Barolli, L., Koyama, A., and Shiratori, N., (2003), A QoS Routing Method for Ad-Hoc Networks Based on Genetic Algorithm, International Workshop on Database and Expert Systems Applications, 14, 1-5.

[12] Chiang, Ch,.Gerla, M., and Zhang, L., (1998), Forwarding Group Multicast Protocol (FGMP) for Multihop, Mobile Wireless Networks, CLUSTER COMPUTING, 1-16.

[13] Deb, K., Dhebar, Y., D., and Pavan, N., V., R., (1998), Non-Uniform Mapping in Binary-Coded Genetic Algorithms, Kanpur Genetic Algorithms Laboratory (KanGAL).

[14] Denardin, G., W., Barriquello, C. H., Campos, A., and Prado, R. N., (2011), A Geographic Routing Hybrid Approach for Void Resolution in Wireless Sensor Networks, Journal of Systems and Software, 10(84), 1577-1590.

[15] Du, K., and Yang, Y., (2010), A QoS routing for Maximum Bandwidth in Ad Hoc Networks, International Conference on Future Networks, 343-345.

[16] Duncan, N., and Eddie, B. T., (2012), An Energy-Efficient Dynamic Source Routing Protocol for Mobile Ad-Hoc Networks, International Journal of Computing and ICT Research, 2(6), 23-32.

[17] Fuhrmann, Th., Pengfei, D., Kutzner, K., and Cramer, C., (2006), Pushing Chord into the Underlay: Scalable Routing for Hybrid MANETs (PDF). System Architecture Group, Technical University of Karlsruhe (TH).

[18] Gani, A., Han, Q., Anuar, N. B., and Zakaria, O., (2009), Enhancing DSR Protocol Performance in Mobile Ad-Hoc Networks Using ACK Reply, WSEAS Transactions on Communications, 2(8), 227-236.

[19] Goyal, M., Soperi, M., Bacceli, E., Chaudhury, G., Shahik, A., Hosseini, H., and Trivedi, K., (2012), Improving Convergence Speed and Scalability in OSPF: A Survey, IEEE COMMUNICATIONS SURVEYS \& TUTORIALS, 14(2), 443-463.

[20] Grover, D., and Singh, G., (2012), Implementation: DSR \& AODV, International Journal of Computer Application, 2(5), 66-79.

[21] Guizani, B., Ayeb, B., Koukam, A., (2012), A New Cluster-Based Link State Routing for Mobile Ad Hoc Networks, IEEE, The 2nd International Conference on Communications and Information Technology (ICCIT): Communication Networks and Systems, Hammamet, 2 , 196-201.

[22] Gujral, R., Rana, S., and Chaudhari, A., (2012), Study and Comparison of Mesh and Tree Based Multicast Routing Protocols for MANETs, International Journal of Latest Trends in Engineering and Technology (IJLTET), 1(2), 58-65.

[23] Gulati, M., K., and Kumar, K., (2013), A Review of QoS Routing Protocols in MANETs, International Conference on Computer Communication and Informatics, 1-6.

[24] Hao, L., (2009), The QoS Routing Protocol in the Ad Hoc Networks, International Conference on Networking and Digital Society, $101-103$.

[25] Hosseini Seno, S. A., Budiarto, R., and Wan, T. Ch., (2011), A Secure Mobile Ad hoc Network Based on Distributed Certificate Authority, Arabian Journal for Science and Engineering, 2(36), 245-257.

[26] Hwang, R., H., Do, W., Y., and Yang, Sh., Ch., (2000), Multicast Routing Based on Genetic Algorithms, JOURNAL OF INFORMATION SCIENCE AND ENGINEERING, 16, 885-902.

[27] Johnson, D., B., Maltz, D., A., and Broch, J., (2001), DSR: The Dynamic Source Routing Protocol for Multi-Hop Wireless Ad Hoc Networks, Monarch, 1-25.

[28] Johnson, D., Hu, Y., and Maltz, D., (2007), The Dynamic Source Routing Protocol (DSR) for Mobile Ad Hoc Networks for IPv4 (RFC 4728), IETF, 1-107.

[29] Karibasappa, A., S., G., and Muralidhara, K., N., (2011), Neuro Fuzzy Based Routing Protocol for Mobile Ad-Hoc Networks, International Conference on Industrial and Information Systems, 6, 216-221.

[30] Katoch, Sh., and Aggarwal, R., (2013), Enhancement in DSR Protocol for Load Balancing and Congestion Control, Global Journal of Computer Science and Technology Network, Web and Security, 7(13),

[31] Kaur, N., and Singh, M., (2012), Effects of Caching on the Performance of DSR Protocol, IOSR Journal of Engineering (IOSRJEN), 2(9), 7-11.

[32] Kojic, N., S., Ivancic, M., B., Z., Reljin, I., S., and Reljin, B., D., (2010), New Algorithm for Packet Routing in Mobile Ad-hoc Networks, JOURNAL OF AUTOMATIC CONTROL, UNIVERSITY OF BELGRADE, 20, 9-16.

[33] kosko, B., (1993), Fuzzy Thinking, Hyperion, New York.

[34] Kumar, M. and Mishra, R. (2012), An Overview of MANET: History, Challenges and Applications, Indian Journal of Computer Science and Engineering (IJCSE), 3, 121-125.

[35] Kunz, Th., and Alhalimi, R., (2010), Energy-efficient proactive routing in MANET: Energy metrics accuracy, Ad Hoc Networks, 7(8), 755-766.

[36] Latiff, L., A., and Fisal, N., (2003), Routing Protocols in Wireless- Mobile Ad Hoc Network - A Review, IEEE, 600-604.

[37] Liu, H., Li, J., Zhang, Y., Q., and Pan, Y., (2005), An Adaptive Genetic Fuzzy Multi-path Routing Protocol for Wireless Ad-Hoc Networks, International Conference on Software Engineering, Artificial Intelligence, Networking and Parallel/Distributed Computing and First ACIS International Workshop on Self-Assembling Wireless Networks, 6, 1-8.

[38] Lou, Y., Zhang, W., and Hu, Y., (2010), A New Cluster Based Routing Protocol for VANET, Second International Conference on Networks Security, Wireless Communications and Trusted Computing, 48, 176-180.

[39] Michalewicz, Z., (2001), Genetic Algorithms, Numerical Optimization, and Constraints, Polish Academia of Science, 1-8.

[40] Mohammed, A., A., and Nagib, G., (2012), Optimal Routing In Ad-Hoc Network Using Genetic Algorithm, Int. J. Advanced Networking and Applications, 3(5), 1323-1328.

[41] Nallusamy, R., Duaiswamy, K., Muthukumar, D., and Sathiakumar, C., (2010), Energy efficient dynamic shortest path routing in Wireless Ad hoc Sensor Networks using Genetic Algorithm, ICWCSC.

[42] Perkins, Ch., E., and Royer, E., M., (1997), Ad-hoc On-demand Distance Vector Routing, IEEE, 1-11.Perkins, Ch., E., and Royer, E., M., (2003), Ad hoc On-Demand Distance Vector (AODV) Routing (RFC 3561), IETF, 1-37.

[43] Ragunath, V., (2004), Implementation of DSR Protocol in NS2 simulator, University of Bonn, Informatik Department IV, 1-5.

[44] Ramesh, V., Subbaiah, P., and Supriya, K., (2010), Modified DSR (Preemptive) to Reduce Link Breakage and Routing Overhead for MANET Using Proactive Route Maintenance (PRM), Global Journal of Computer Science and Technology, 5(9), 124-129.

[45] Rifa-Pous, H., and Herrera-Joancomarti, J., (2011), Computational and Energy Costs of Cryptographic Algorithms on Handheld Devices, Future Internet, 3, 31-48.

[46] Roshankar, R., Bhatia, R., Shrivatava, V., and Sharma, D., K., (2012), Performance Analysis of Various Routing Protocols (Proactive and Reactive) for Random Mobility Models of Adhoc Networks, Recent Advances in Information Technology, 1, 1-5.

[47] Royer, E., M., (1999), A Review of Current Routing Protocols for Ad Hoc Mobile Wireless Networks, IEEE Personal Communications, $99,46-55$.

[48] Saeed, N., H., Abbod, M., F., and Al-Raweshidy, H., S., (2012), MANET Routing Protocols Taxonomy, International Conference on Future Communication Networks, 123-128.

[49] Saleh, R., O., M., Saman, M., Y., M., and Rahman, M., N., A., (2012), Fresh Shortest Route Algorithm for DSR Protocol in Mobile Ad-Hoc Networks, International Annual Symposium on Sustainability Science and Management, 11, 1068-1073. 
[50] Sarr, Ch., Chaudet, C., Chelius, G., and Lassous, I., G., (2005), A node-based available bandwidth evaluation in IEEE 802.11 ad hoc networks, International Journal of Parallel, Emergent and Distributed Systems, 1-21.

[51] Sihai, Zh., Layuan, L., and Yong, L. (2011), A QoS-based Routing Algorithm in Ad Hoc Network, International Symposium on Distributed Computing and Applications to Business, Engineering and Science, 10, 23-26.

[52] Tan, K., Zhang, Q., and Zhu, W., (2003), Shortest Path Routing in Partially Connected Ad Hoc Networks, GLOBECOM, 10381042 .

[53] Tong, F., Tang, W., Peng, L., Xie, R., Yang, W., and Kim, Y., (2010), A Node-Grade Based AODV Routing Protocol for Wireless Sensor Network, 2010 Second International Conference on Networks Security Wireless Communications and Trusted Computing (NSWCTC), 2, 180-183.

[54] Wismanath, K., Obraczka, K., and Tsudik, G., (2005), Exploring Mesh- and Tree Based Multicast Routing Protocols for MANETs, $1-45$.

[55] Wu, H., and Jia, X., (2007), QoS Multicast Routing by Using Multiple Paths/Trees in Wireless Ad hoc networks, FFCSA, 559-612.

[56] Xiaochuan, X., Gang, W., Keping, W., Gang, W., and Shilou, J., (2009), Link reliability based hybrid routing for tactical mobile ad hoc network, Journal of Systems Engineering and Electronics, 2(19),259-267.

[57] Yeh, Ch., T., (2009), Approximations by interval, triangular and trapezoidal fuzzy numbers, IFSA-EUSFLAT, 143-148.

[58] Zafar, H., Hassan, L., Khattak, A., Mufti, Z., and Jan, S., (2012), Implementation of the Dynamic Source Routing Protocol in Network Simulator 2 - An Overview, SINDH UNIVERSITY RESEARCH JOURNAL (SCIENCE SERIES), 44(3), 491 -496. 